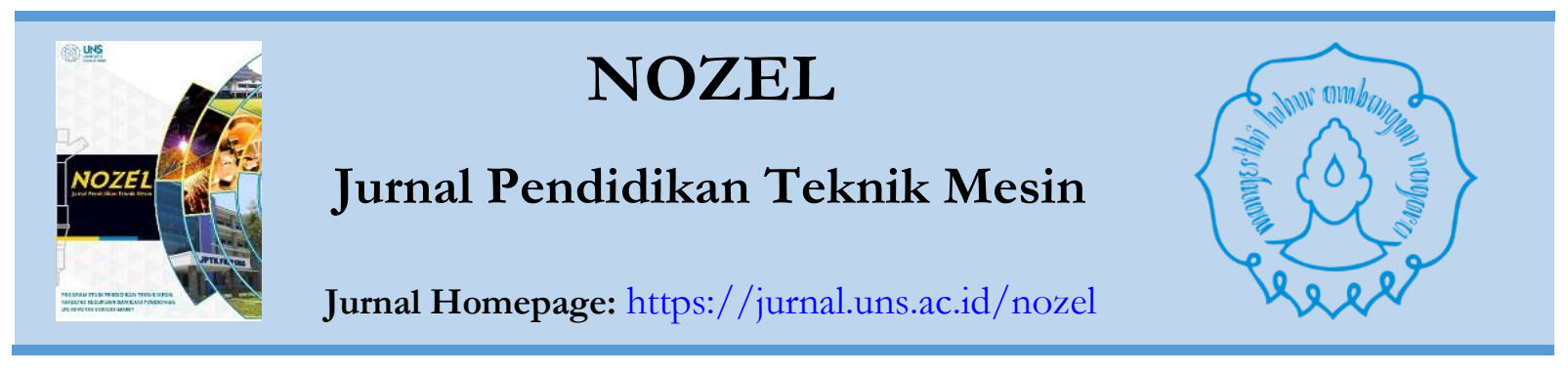

\title{
PENGEMBANGAN MEDIA PEMBELAJARAN CNC BERBASIS PERANGKAT LUNAK ANIMASI
}

\author{
Dwi Kusuma Ulinnuha ${ }^{1}$, Budi Harjanto ${ }^{1}$, Indah Widiastuti ${ }^{1}$ \\ ${ }^{1}$ Program Studi Pendidikan Teknik Mesin, FKIP, Universitas Sebelas Maret Surakarta \\ e-mail: ulinnuhadwi@gmail.com
}

\begin{abstract}
This research aims to (1) develop an instructional material based animation software for CNC course, (2) evaluate instructional material for CNC course that has been developed. The research was conducted at the Department of Mechanical Engineering Education, Faculty of Teacher Training and Education, Sebelas Maret University Surakarta. This research used Multimedia Development Life Cycle (MDLC) as research procedure, which consists of six stages, concept, design, collecting material, assembly, testing and distribution. Evaluation of instructional material for CNC course was performed by ask potential users to operate CNC instructional material that have been developed, then get response from potential users through a questionnaire. Potential users are divided into two categories, lecturers of $C N C$ and CAM courses and students of Mechanical Engineering Education who take CNC and CAM courses in the academic year 2015/2016. Questionnaire for lecturers of $C N C$ and $C A M$ course reviewing instructional material from aspects of learning content, interaction, and presentation of the material. The questionnaire was given to 3 lecturers consisting of 15 point statements with Rating Scale as assessment system on intervals 1-5. Questionnaire for student reviewing instructional material from aspect of learning motivation as one of instructional material function. Questionnaire was given to 26 students consisting of 20 point statements with Likert Scale as assessment system on intervals 1-5. The results of the research show (1) the development of instructional material for CNC course used Adobe Flash CS6 as main software with MDLC as development procedure, (2) the evaluation results show the instructional material for CNC course that developed gets (a) in aspects of learning content, interaction, and presentation of the material, the instructional material for CNC course gets very good category with percentage 90,22\%, (b) in the aspect of learning motivation as one of instructional material function, the instructional material for CNC course gets good categories with percentage 78,39\%.
\end{abstract}

Keywords: Instructional Material, CNC, Adobe Flash, Animation

\section{A. PENDAHULUAN}

Penggunaan media pembelajaran

dalam proses pembelajaran penting adanya. Asyhar (2012) berpendapat bahwa peningkatan mutu pembelajaran merupakan salah satu poin pentingnya penggunaan media pembelajaran. Dalam proses pembelajaran media memiliki fungsi sebagai pembawa informasi dari sumber (guru) menuju penerima (siswa) 
(Daryanto, 2012: 8). Ini berarti peran media dalam proses pembelajaran sangat penting yaitu sebagai perantara informasi antara guru dengan siswa. Informasi yang disampaikan oleh guru melalui media harus dapat diterima oleh siswa secara utuh agar proses pembelajaran menjadi lebih efektif.

Pemanfaatan media pembelajaran yang kurang optimal dapat mempengaruhi efektifitas proses pembelajaran. Dengan optimalisasi pemanfaatan media pembelajaran, maka proses pembelajaran akan berjalan lebih efektif. Siswa akan merasa lebih antusias, tertarik, dan termotivasi dalam mengikuti proses pembelajaran. Arsyad (2007: 16) mengemukakan bahwa selain membangkitkan motivasi dan minat siswa, media pembelajaran juga dapat membantu siswa meningkatkan pemahaman, menyajikan data dengan menarik dan terpercaya, memudahkan penafsiran data, dan memadatkan informasi.

Media pembelajaran yang cukup banyak dikembangkan ialah media yang berbasis pada perangkat lunak animasi. Perangkat lunak itu mampu menyajikan informasi, baik dari segi audio, visual, maupun audiovisual, atau dapat disebut sebagai multimedia. Perangkat lunak itu juga mampu menyajikan simulasi-simulasi yang memungkinkan terjadinya interaksi antara media dan pengguna. Interaksi antara media dan pengguna itu dapat memudahkan penyerapan informasi yang disampaikan. Hal itu merupakan modal utama untuk menjadi media pembelajaran yang baik.

Dalam penelitian Aziz (2015) pengembangan media pembelajaran yang berbasis pada perangkat lunak animasi menunjukkan bahwa minat belajar siswa meningkat. Peningkatan itu ditunjukkan dengan persentase angket minat belajar siswa yang memperoleh skor $80 \%$ dan didukung ketuntasan persentase kriteria ketuntasan minimal (KKM). Ini menunjukkan bahwa penggunaan media pembelajaran interaktif yang berbasis perangkat lunak animasi merupakan media yang cukup efektif dalam memudahkan penyerapan informasi yang disampaikan oleh guru kepada siswa.

Berkaitan dengan potensi itu, penggunaan media pembelajaran berbasis perangkat lunak pembuat animasi dalam mata kuliah CNC (Computer Numerical Control) dan CAM (Computer Aided Manufacturing), yang merupakan salah satu mata kuliah wajib di Program Studi Pendidikan Teknik Mesin FKIP Universitas Sebelas Maret, dapat membantu memudahkan penyerapan 
informasi yang disampaikan oleh dosen kepada mahasiswa. Pasalnya, ada beberapa kendala dalam proses pembelajaran pada mata kuliah itu yang menyebabkan kurang efektifnya proses pembelajaran. Beberapa kendala yang dialami antara lain kurang optimalnya penggunaan media pembelajaran yang mampu menggambarkan pergerakan-pergerakan mesin CNC dengan jelas, terbatasnya waktu praktik, tidak sebandingnya jumlah mahasiswa dengan jumlah mesin, serta kondisi mesin yang kurang prima. Ini mengakibatkan mahasiswa kurang mampu menyerap informasi yang disampaikan oleh dosen.

Penggunaan media pembelajaran seperti Microsoft Power Point, Cut Viewer dan Master CAM telah dilakukan untuk mengatasi kendala-kendala itu. Namun, pemanfaatan media pembelajaran itu masih kurang optimal karena belum adanya penggunaan media pembelajaran CNC yang dapat mensimulasikan pengoperasian mesin CNC. Simulator mesin CNC ini dapat mengoptimalkan proses pembelajaran karena mampu menampilkan simulasi pengoperasian mesin CNC tanpa menghadirkan mesin CNC yang sesungguhnya.

Telah ada beberapa penelitian yang mengembangkan media pembelajaran
CNC berbasis perangkat lunak animasi. Beberapa penelitian itu antara lain penelitian Harjanto (2009), Purwoko (2009), Nugroho (2014) dan Sehono (2014). Hasil dari keempat penelitian itu menyatakan bahwa media pembelajaran itu telah memenuhi persyaratan sebagai media pembelajaran yang layak digunakan. Namun, pengembangan media pembelajaran $\mathrm{CNC}$ terhitung masih belum banyak dilakukan mengingat terdapat berbagai jenis mesin $\mathrm{CNC}$ yang ada.

Berdasarkan uraian di atas, pengembangan media pembelajaran $\mathrm{CNC}$ berbasis perangkat lunak animasi perlu dilakukan. Pengembangan media pembelajaran CNC bertujuan guna memberikan gambaran yang lebih jelas mengenai materi tentang mesin $\mathrm{CNC}$, menampilkan animasi pergerakanpergerakan mesin $\mathrm{CNC}$, dan mensimulasikan pengoperasian mesin CNC, sehingga informasi yang disampaikan kepada mahasiswa dapat diterima dengan baik dan efektif.

Penelitian ini bertujuan untuk mengembangkan media pembelajaran CNC berbasis perangkat lunak animasi. Setelah media pembelajaran CNC berbasis perangkat lunak animasi dikembangkan, media pembelajaran $\mathrm{CNC}$ itu dievaluasi melalui pengujian penggunaan kepada 
calon pengguna dan menggali respon calon pengguna terkaim media pembelajaran $\mathrm{CNC}$ yang telah dikembangkan.

\section{Media Pembelajaran}

Media pembelajaran merupakan sarana perantara dalam proses pembelajaran (Daryanto, 2012: 4). Asyhar (2012: 8) bahwa media pembelajaran adalah segala sesuatu yang dapat menyampaikan atau menyalurkan pesan dari suatu sumber secara terencana, sehingga terjadi lingkungan belajar yang kondusif di mana penerimanya dapat melakukan proses belajar secara efisien dan efektif. Putra F.M. (2015: 9), media pembelajaran dapat diartikan sebagai segala sesuatu yang digunakan untuk menyalurkan pesan dari pengirim (guru) ke penerima (siswa) sehingga dapat merangsang pikiran, perasaan, perhatian dan minat serta perhatian siswa sehingga kegiatan belajar terjadi secara efektif dan efisien serta dengan hasil yang optimal. Media pembelajaran merupakan segala bentuk sarana dalam proses pembelajaran yang berfungsi untuk menyampaikan pesan atau informasi dari pengirim (pendidik) kepada penerima (peserta didik) sehingga proses pembelajaran dapat berjalan efektif dan efisien.

\section{Perangkat Lunak Animasi}

Perangkat lunak (software) merupakan salah satu komponen dasar komputer selain perangkat keras (hardware) dan pengguna/user (brainware). Mulyanto (2008: menyatakan bahwa perangkat lunak adalah seluruh perintah yang digunakan untuk memproses informasi. Rahman dan Alfaizi (2014: 3) menyatakan bahwa perangkat lunak adalah program komputer yang berfungsi sebagai sarana interaksi (penghubung) antara pengguna (user) dan perangkat keras (hardware). Software dapat juga dikatakan sebagai penerjemah perintah-perintah yang dijalankan pengguna komputer untuk diproses oleh perangkat keras (hardware). Perangkat lunak animasi dapat diartikan sebagai program komputer yang berfungsi sebagai penghubung antara pembuat animasi dengan perangkat keras (komputer) dalam upaya untuk membuat suatu animasi.

\section{B. METODE}

Penelitian ini menggunakan prosedur pengembangan media pembelajaran $\mathrm{CNC}$ merujuk pada model pengembangan MDLC (Multimedia Development Life Cycle). Model ini terdiri dari enam langkah meliputi konsep, desain, 
pengumpulan material, penyusunan, pengujian, dan distribusi.

Angket untuk mahasiswa

Teknik pengumpulan data yang digunakan oleh Hong dkk. (2015) pada digunakan yaitu studi literatur, penelitiannya. Angket ini berisi tinjauan dokumentasi, dan kuesioner. Sampel yang tentang media pembelajaran dilihat dari digunakan yaitu mahasiswa Pendidikan aspek motivasi belajar siswa sebagai salah Teknik Mesin FKIP Universitas Sebelas Maret angkatan tahun 2013 yang menempuh mata kuliah CNC dan CAM tahun akademik 2015/2016.

satu fungsi media pembelajaran. Angket diberikan pada 26 mahasiswa yang terdiri dari 20 butir pernyataan dengan sistem penilaian Likert Scale dengan interval 1 s.d 5 .

\section{Instrumen Penelitian}

Pada penelitian ini instrumen penelitian yang digunakan berupa angket atau kuesioner. Terdapat 2 jenis angket yang digunakan yaitu angket untuk dosen pengampu mata kuliah CNC dan CAM dan angket untuk mahasiswa PTM konsentrasi Produksi yang mengambil mata kuliah CNC dan CAM pada tahun akademik 2015/2016.

Pada penelitian ini angket untuk dosen pengampu mata kuliah CNC menggunakan angket yang pernah digunakan oleh Rizkiansyah (2013) dalam penelitiannya. Angket ini berisi tinjauan tentang media pembelajaran dilihat dari aspek materi pembelajaran, interaksi, dan penyajian materi. Angket diberikan pada 3 dosen yang terdiri dari 15 butir pernyataan dengan sistem penilaian Rating Scale dengan interval 1 s.d. 5.

\section{Analisis Data}

Penelitian ini menggunakan analisis deskriptif yang digunakan untuk mendeskripsikan data dengan sejelasjelasnya dari data hasil pengisian angket oleh calon pengguna sebagai responden. Untuk keperluan analisis kuantitatif, data yang telah dikumpulkan dari angket diberi kategori berbobot skor 1 s.d 5. Analisis data angket diolah dengan menjumlahkan bobot skor alternatif jawaban yang telah dipilih pada masing-masing pertanyaan yang diberikan. Jumlah itu kemudian dibagi dengan skor ideal yang dapat diperoleh. Hasil itu kemudian dikalikan $100 \%$ untuk mendapatkan persentasenya.

Hasil persentase respon calon pengguna itu kemudian diubah menjadi kriteria penilaian media pembelajaran CNC yang dapat dijelaskan pada tabel 1 . 
Tabel 1. Kriteria Penilaian Media Pembelajaran CNC

\begin{tabular}{|ccc|} 
No & Persentase & Kriteria \\
\hline 1 & $<20 \%$ & Sangat tidak baik \\
2 & $21-40 \%$ & Tidak baik \\
3 & $41-60 \%$ & Cukup baik \\
4 & $61-80 \%$ & Baik \\
5 & $81-100 \%$ & Sangat baik \\
\hline
\end{tabular}

\section{HASIL DAN PEMBAHASAN}

Proses Pengembangan Media

\section{Pembelajaran CNC}

\section{Konsep Pengembangan Media Pembelajaran CNC}

Pengembangan media pembelajaran CNC ini bertujuan untuk memberikan gambaran yang lebih jelas mengenai materi pembelajaran $\mathrm{CNC}$, menampilkan animasi pergerakan-pergerakan mesin $\mathrm{CNC}$, dan mensimulasikan pengoperasian mesin CNC. Hal ini perlu dilakukan karena ada beberapa kendala yang terjadi dalam pembelajaran pada mata kuliah CNC dan CAM yang menyebabkan kurang efektifnya proses pembelajaran. Beberapa kendala itu antara lain kurang optimalnya penggunaan media pembelajaran yang mampu menggambarkan pergerakanpergerakan mesin CNC dengan jelas, terbatasnya waktu praktik, tidak sebandingnya jumlah mahasiswa dengan jumlah mesin, serta kondisi mesin yang kurang prima.
Penggunaan media pembelajaran seperti Power Point, Cut Viewer dan Master CAM telah dilakukan untuk mengatasi kendala-kendala itu. Namun, pemanfaatan media pembelajaran itu masih kurang optimal karena belum adanya penggunaan media pembelajaran $\mathrm{CNC}$ yang dapat mensimulasikan pengoperasian mesin CNC. Simulator mesin CNC ini dapat mengoptimalkan proses pembelajaran karena mampu menampilkan simulasi pengoperasian mesin CNC tanpa menghadirkan mesin $\mathrm{CNC}$ yang sesungguhnya. Pengembangan media pembelajaran $\mathrm{CNC}$ diperlukan agar informasi yang disampaikan oleh dosen kepada mahasiswa dapat diterima dengan secara utuh dan efektif.

Media pembelajaran CNC ini dikembangkan menggunakan perangkat lunak animasi sebagai perangkat lunak utama. Perangkat lunak animasi yang digunakan yaitu Adobe Flash CS6. Pengembangan media pembelajaran CNC ini diarahkan menjadi media pembelajaran interaktif yang memungkinkan terjadinya interaksi antara media dan pengguna.

\section{Desain Media Pembelajaran CNC}

Desain media pembelajaran $\mathrm{CNC}$ meliputi pembuatan storyboard media pembelajaran CNC, pembuatan flowchart tampilan media pembelajaran $\mathrm{CNC}$, dan 
pembuatan struktur navigasi media pembelajaran $\mathrm{CNC}$.

\section{a. Pembuatan Storyboard}

Storyboard pada media pembelajaran $\mathrm{CNC}$ ini terbagi ke dalam 7 scene utama. Scene pertama sebagai halaman pembukaan, scene kedua sebagai halaman home, scene ketiga sebagai halaman menu sub materi, scene keempat sebagai halaman materi pembelajaran, scene kelima sebagai halaman video pembelajaran, scene keenam sebagai halaman simulasi mesin $\mathrm{CNC}$, dan scene ketujuh sebagai halaman bantuan dan halaman info.

\section{b. Pembuatan Flowchart}

Flowchart merupakan gambaran yang memperlihatkan urutan proses dari suatu produk (video, aplikasi, game, iklan, media pembelajaran interaktif, dan lainlain) yang akan dihasilkan. Pembuatan flowchart bertujuan untuk mempermudah dan memperjelas alur media pembelajaran CNC yang akan dibuat.

\section{c. Pembuatan Struktur Navigasi}

Struktur navigasi dalam media pembelajaran $\mathrm{CNC}$ ini dirancang agar halaman utama memungkinkan memiliki hubungan dengan setiap konten yang ada pada media pembelajaraan CNC. Setiap konten dapat kembali ke halaman utama, halaman info, dan halaman bantuan. Hal ini dirancang agar memudahkan pengguna dalam mencari konten dan sub konten pada media pembelajaran CNC. Semua menu maupun sub menu konsisten tersaji dalam setiap konten.

\section{Pengumpulan Material Media Pembelajaran CNC}

Pengumpulan material dilakukan sesuai dengan desain yang telah dibuat sebelumnya. Dari desain yang telah dirancang, diperoleh material-material yang dibutuhkan dalam mengembangkan media pembelajaran $\mathrm{CNC}$ antara lain materi pembelajaran, font, grafik, audio, video, dan software-software.

\section{Pembuatan dan Penyusunan Media}

\section{Pembelajaran CNC}

Material yang telah dikumpulkan, dirangkai dan disusun sesuai dengan desain. Proses Pembuatan media pembelajaran terdiri dari dua file utama yaitu file induk dan file pendukung. File induk terdiri dari beberapa halaman untuk menempatkan file pendukung. File induk terdiri dari halaman pembukaan, halaman utama, halaman, bantuan, halaman info, halaman materi, dan halaman sub materi. Setiap halaman terdapat tombol navigasi yang terdiri dari tombol home, mute/unmute, about, help, dan exit kecuali halaman pembukaan yang hanya terdapat tombol navigasi mute/unmute, exit, dan 
start. Halaman materi terdiri dari 4 halaman, berisi tombol untuk menuju ke halaman sub materi. Halaman sub materi terdiri dari 7 halaman berisikan 7 sub materi pembelajaran.

File pendukung terdiri dari beberapa file materi pembelajran. File materi terdiri dari 7 file materi pembelajaran, yaitu materi CNC, Pemrograman Dasar CNC, Pemrograman CNC Bubut, Pemrograman CNC Frais, Pengoperasian CNC Bubut, Pengoperasian CNC Frais, Video Pengoperasian Mesin CNC Bubut, Video Pengoperasian Mesin CNC Frais, Simulasi Mesin CNC Bubut, Simulasi Mesin CNC Frais.
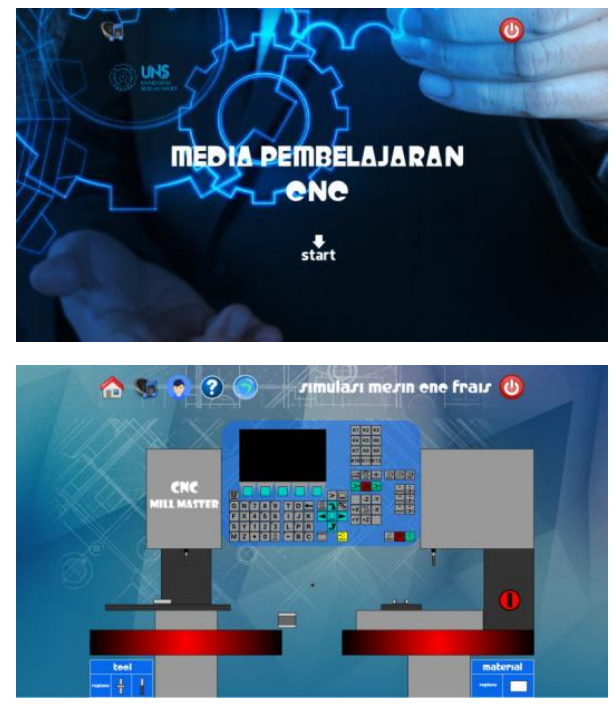

Gambar 1. Contoh Tampilan Media Pembelajaran CNC

Seluruh file yang telah dibuat dan disesuaikan dengan kebutuhan media pembelajaran $\mathrm{CNC}$, kemudian disusun sesuai dengan storyboard yang telah dibuat. Untuk keperluan pemrograman dan pengintegrasian tiap file digunakan sebuah bahasa pemrograman software Adobe Flash CS6 yang dikenal dengan nama Action Script 3.0.

Berdasarkan storyboard yang telah dibuat, isi dari media pembelajaran $\mathrm{cnc}$ dapat dibagi dalam 7 tampilan utama, yaitu halaman pembukaan, halaman beranda (home), halaman sub materi, halaman materi pembelajaran, halaman video pembelajaran, halaman simulasi, halaman info dan bantuan.

\section{Hasil Evaluasi Media Pembelajaran CNC}

\section{Data Respon Dosen}

Pengisian angket respon tiga dosen pengampu mata kuliah CNC dan CAM terhadap media pembelajaran $\mathrm{CNC}$ diperoleh hasil seperti pada Tabel 2.

Tabel 2 menunjukkan perhitungan total skor dan rata-rata skor tiap butir angket dari tiga responden. Terdapat 3 butir angket yang memperoleh total skor terendah yaitu dengan total perolehan skor 12 dengan rata-rata skor 4,00 dan terdapat 2 butir angket yang memperoleh total skor tetinggi yaitu dengan total perolehan skor 15 dengan rata-rata skor 5,00. Tiga butir angket yang memperoleh skor terendah yaitu butir ke-1 terkait dengan pernyataan 
bahwa media pembelajaran CNC memiliki tujuan pembelajaran yang jelas, butir ke-3 mengenai pernyataan bahwa media pembelajaran CNC memiliki kejelasan materi dan butir ke-14 terkait dengan pernyataan bahwa media pembelajaran CNC menggunakan bahasa yang mudah dipahami. Berdasarkan Tabel 1, walaupun ketiga butir angket itu memperoleh ratarata skor terendah yaitu 4,00, rata-rata skor 4,00 masih tergolong dalam kategori baik.

Tabel 2. Hasil Pengisian Angket Respon Dosen

\begin{tabular}{|c|c|c|c|}
\hline No & $\begin{array}{c}\text { No } \\
\text { Butir }\end{array}$ & $\begin{array}{l}\text { Total } \\
\text { Skor }\end{array}$ & $\begin{array}{c}\text { Skor Rata- } \\
\text { rata }\end{array}$ \\
\hline 1 & 1 & 12 & 4,00 \\
\hline 2 & 2 & 13 & 4,33 \\
\hline 3 & 3 & 12 & 4,00 \\
\hline 4 & 4 & 15 & 5,00 \\
\hline 5 & 5 & 15 & 5,00 \\
\hline 6 & 6 & 14 & 4,67 \\
\hline 7 & 7 & 14 & 4,67 \\
\hline 8 & 8 & 14 & 4,67 \\
\hline 9 & 9 & 13 & 4,33 \\
\hline 10 & 10 & 13 & 4,33 \\
\hline 11 & 11 & 14 & 4,67 \\
\hline 12 & 12 & 14 & 4,67 \\
\hline 13 & 13 & 14 & 4,67 \\
\hline 14 & 14 & 12 & 4,00 \\
\hline 15 & 15 & 14 & 4,67 \\
\hline \multicolumn{2}{|c|}{ Total } & 203 & 67,67 \\
\hline
\end{tabular}

Dua butir angket yang memperoleh total skor tertinggi adalah butir ke-4 terkait pernyataan relevansi materi pada media pembelajaran $\mathrm{CNC}$ dan pada butir ke-5 terkait pernyataan tentang keruntutan materi pada media pembelajaran $\mathrm{CNC}$ dengan rata-rata skor
5,00. Berdasarkan Tabel 1, rata-rata skor 5,00 termasuk dalam kategori sangat baik. Total skor seluruh butir angket dari 3 responden diperoleh total skor 203. Persentase respon dosen terhadap media pembelajaran $\mathrm{CNC}$ diperoleh perhitungan persentase sebesar 90,22\%. Kriteria penilaian media pembelajaran $\mathrm{CNC}$ pada Tabel 3.3, menunjukkan bahwa persentase sebesar 90,22\% termasuk dalam kategori sangat baik. Dengan demikian, media pembelajaran CNC yang dikembangkan dapat dikatakan mendapat kategori sangat baik dalam aspek materi pembelajaran, interaksi, dan penyajian materi.

\section{Data Respon Mahasiswa}

Angket yang diberikan pada responden mahasiswa berjumlah 26 angket. Dari 26 angket yang diberikan pada responden, angket yang kembali sejumlah 23 angket. Pengisian angket respon mahasiswa terhadap media pembelajaran CNC diperoleh hasil seperti tabel 3 .

Tabel 3 menunjukkan perhitungan total skor dan rata-rata skor tiap butir angket dari 23 responden. Butir angket ke19 yaitu pernyataan bahwa ada beberapa bagian media pembelajaran $\mathrm{CNC}$ yang tidak dimengerti oleh responden, memperoleh total skor terendah yaitu 
dengan total skor 69 dengan rata-rata skor 3,00. Berdasarkan Tabel 1, rata-rata skor 3,00 termasuk dalam kategori cukup baik.

Tabel 3. Hasil Pengisian Angket Respon Mahasiswa

\begin{tabular}{cccc}
\hline No & $\begin{array}{c}\text { No } \\
\text { Butir }\end{array}$ & $\begin{array}{c}\text { Total } \\
\text { Skor }\end{array}$ & $\begin{array}{c}\text { Skor } \\
\text { Rata-rata }\end{array}$ \\
\hline 1 & 1 & 103 & 4,48 \\
2 & 2 & 90 & 3,91 \\
3 & 3 & 96 & 4,17 \\
4 & 4 & 95 & 4,13 \\
5 & 5 & 81 & 3,52 \\
6 & 6 & 99 & 4,30 \\
7 & 7 & 93 & 4,04 \\
8 & 8 & 87 & 3,78 \\
\hline 9 & 9 & 81 & 3,52 \\
10 & 10 & 95 & 4,13 \\
\hline 11 & 11 & 86 & 3,74 \\
12 & 12 & 91 & 3,96 \\
13 & 13 & 93 & 4,04 \\
14 & 14 & 82 & 3,57 \\
15 & 15 & 86 & 3,74 \\
16 & 16 & 92 & 4,00 \\
17 & 17 & 89 & 3,87 \\
\hline 18 & 18 & 100 & 4,35 \\
\hline 19 & 19 & 69 & 3,00 \\
\hline 20 & 20 & 95 & 4,13 \\
\hline \multicolumn{2}{c}{ Total } & 1803 & 78,39 \\
\hline \multicolumn{5}{c}{} & & \\
\hline
\end{tabular}

Hal ini menunjukkan bahwa masih ada beberapa bagian dari media pembelajaran $\mathrm{CNC}$ yang belum dimengerti oleh pengguna. Bagian yang belum dimengerti oleh pengguna dimungkinkan terdapat pada bagian simulasi mesin $\mathrm{CNC}$ karena belum ada petunjuk penggunaan simulasi. Oleh karena itu, bagian ini perlu ditambahkan petunjuk penggunaan agar tidak lagi membingungkan pengguna.
Total skor tertinggi diperoleh butir angket ke-1 yaitu pernyataan bahwa media pembelajaran $\mathrm{CNC}$ dapat menarik perhatian responden dengan perolehan total skor 103 dengan rata-rata skor 4,48. Berdasarkan Tabel 1, rata-rata skor 4,48 termasuk dalam kategori baik.

Total skor seluruh butir angket dari 23 responden diperoleh skor 1803. Persentase respon mahasiswa terhadap media pembelajaran $\mathrm{CNC}$ diperoleh hasil perhitungan persentase sebesar 78,39\%. Kriteria penilaian media pembelajaran CNC pada Tabel 3.3, menunjukkan bahwa persentase sebesar 78,39\% termasuk dalam kategori baik. Dengan demikian, media pembelajaran CNC yang dikembangkan dapat dikatakan mendapat kategori baik dalam aspek motivasi belajar sebagai salah satu fungsi media pembelajaran.

\section{PENUTUP}

\section{Simpulan}

Berdasarkan hasil pengembangan media pembelajaran $\mathrm{CNC}$, kesimpulan yang dapat diambil antara lain:

1. Proses pengembangan Media Pembelajaran CNC ini dikembangkan dengan langkah-langkah sebagai berikut:

a. Konsep, yaitu proses perumusan dasar-dasar dari media pembelajaran 
CNC yang akan dibuat meliputi tujuan dan jenis media yang akan dikembangkan.

b. Desain/rancangan, yaitu proses penjabaran pembuatan storyboard media pembelajaran $\mathrm{CNC}$, pembuatan flowchart tampilan media pembelajaran $\mathrm{CNC}$, dan pembuatan struktur navigasi media pembelajaran CNC.

c. Pengumpulan material, yaitu proses pengumpulan material yang dibutuhkan dalam proses pembuatan media Pembelajaran CNC antara lain materi pembelajaran, font, grafik, audio, video, dan software-software yang dibutuhkan.

d. Penyusunan, yaitu proses di mana media pembelajaran CNC yang akan dihasilkan, dirangkai dan disusun sesuai dengan desain yang telah dibuat. Material yang telah dikumpulkan, dirangkai dan disusun sesuai dengan desain. Proses Pembuatan media pembelajaran terdiri dari dua file utama yaitu file induk dan file pendukung.

e. Pengujian, yaitu proses di mana calon pengguna diminta untuk menggunakan media pembelajaran CNC yang telah dikembangakan, kemudian menggali respon dari calon pengguna terhadap media pembelajaran $\mathrm{CNC}$ yang telah dikembangkan melalui angket. Calon pengguna dibagi dalam dua kategori, yaitu dosen pengampu mata kuliah CNC dan CAM dan mahasiswa PTM konsentrasi Produksi yang mengambil mata kuliah $\mathrm{CNC}$ dan CAM pada tahun ajaran 2015/2016.

2. Hasil evaluasi media pembelajaran CNC yang telah dikembangakan dibagi dalam dua kategori sebagai berikut:

a. Kategori pertama yaitu respon dosen terhadap media pembelajaran $\mathrm{CNC}$ ditinjau dari aspek materi pembelajaran, interaksi, dan penyajian materi, memperoleh kategori SANGAT BAIK dengan persentase sebesar $90,22 \%$.

b. Kategori yang kedua yaitu respon mahasiswa terhadap media pembelajaran $\mathrm{CNC}$ ditinjau dari aspek motivasi belajar sebagai salah satu fungsi media pembelajaran, memperoleh kategori BAIK dengan persentase sebesar $78,39 \%$.

\section{Saran}

Berdasarkan hasil pengembangan media pembelajaran $\mathrm{CNC}$, saran yang dapat diberikan antara lain:

1. Media pembelajaran CNC yang telah dikembangkan perlu dilakukan 
penyempurnaan dari segi simulasi pengoperasian mesin $\mathrm{CNC}$ dengan pemberian petunjuk pengoperaisan simulasi.

2. Pengembangan media pembelajaran CNC selanjutnya diharapkan dapat mengembangkan simulasi pengoperasian mesin $\mathrm{CNC}$ tiga dimensi (3D), sehingga simulasi pengoperasian mesin $\mathrm{CNC}$ terlihat lebih nyata.

3. Perlu dilakukan evaluasi lebih lanjut terhadap media pembelajaran $\mathrm{CNC}$ yang telah dikembangkan dari aspek fungsi media pembelajaran yang lain.

4. Perlu adanya analisis spesifikasi produk media pembelajaran dari sudut pandang pengguna, tidak hanya dari sudut pandang peneliti agar pengembangan media pembelajaran lebih sesuai dengan keinginan pengguna.

\section{DAFTAR PUSTAKA}

Arsyad, A. (2007). Media Pembelajaran. Jakarta: PT Raja Grafindo Persada.

Asyhar, R. (2012). Kreatif Mengembangkan Media Pembelajaran. Jakarta: Referensi.

Aziz, A.F. (2015). Pengembangan Media Pembelajaran Berbasis Adobe Flash Untuk Meningkatkan Minat Belajar Siswa pada Mata Pelajaran Mekanika Teknik Jurusan Teknik Gambar Bangunan di SMK N 1 Seyegan. Jogjakarta: UNY.
Daryanto. (2012). Media Pembelajaran. Bandung: Satu Nusa.

Harjanto, B. (2009). Pengembangan Multimedia Pembelajaran Interaktif Mata Kuliah CNC pada Program Studi Pendidikan Teknik Mesin JPTK FKIP UNS. Diperoleh dari https://dosen.fkip.uns.ac.id/data/inde x.php?prodi=P22\&id $=1979011$

Mulyanto, A.R., (2008). Rekayasa Perangkat Lunak. Jakarta: Direktorat Pembinaan Sekolah Menengah Kejuruan, Direktorat Jenderal Manajemen Pendidikan Dasar dan Menengah, Departemen Pendidikan Nasional.

Nugroho, K. (2014). Pengembangan Media Pembelajaran CNC PU 3A Milling Menggunakan Multimedia Interaktif Program Flash Sesuai dengan Rancangan Pelaksanaan Pembelajaran Matakuliah CNC Lanjut di Jurusan Teknik Mesin Universitas Negeri Malang. Diperoleh pada 8 Februari 2016, dari http://karya-

ilmiah.um.ac.id/index.php/TM/article /view/36039/0

Purwoko, B.S.H. (2009). Pengembangan Mesin CNC Virtual sebagai Media Interaktif dalam Pembelajaran Pemrograman CNC. Jurnal Penelitian dan Evaluasi Pendidikan. Diperoleh pada 8 Februari 2016, dari http://download.portalgaruda.org/arti cle.php? article $=102634 \& v a l=448$

Putra, F.M. (2015). Pengembangan Media Pembelajaran Metode dan Teknik Lipatan Adonan Pastry dengan Adobe Flash CS6 Untuk Pembelajaran Siswa Patiseri SMK Kelas XI. Laporan Penelitian Tidak Dipublikasikan. Universitas Negeri Yogyakarta, Yogyakarta.

Rahman, W. dan Alfaizi, F. (2014). Mengenal Berbagai Macam 
Software. Diperoleh pada 24 Februari 2014, dari http://kambing.ui.ac.id/onnopurbo/eb ook/ebook-SU2013/SuryaUniv-

Mengenal-berbagai-macamsoftware.pdf

Sehono. (2014). Pengembangan Media Pembelajaran Berbasis Komputer untuk Mata Kuliah CNC pada Program Studi S1 Semester IV Teknik Mesin Universitas Negeri Medan Tahun Ajaran 2013/2014. Diperoleh pada 8 Februari 2016, dari http://digilib.unimed.ac.id/pengemba ngan-media-pembelajaran-berbasis- komputer-untuk-mata-kuliah-cncpada-program-studi-s 1-semester-ivteknik-mesin-universitas-negerimedan-tahun-ajaran-2013201434719.html

Singgih M.L. dan Rahmayanti. (2008). Faktor-Faktor yang Mempengaruhi Kualitas Pendidikan pada Perguruan Tinggi. Prosiding Seminar Nasional Teknosain 2008 Bidang Teknik Industri, C-137. Diperoleh 5 Februari 2016 ,

darihttp://journal.uii.ac.id/index.php/ Teknoin/article/viewFile/2108/1914 